\title{
Capital social versus aislamiento social: los jornaleros migratorios de Tamaulipas ${ }^{1}$
}

\author{
Simón Pedro Izcara Palacios ${ }^{2}$ y Karla Lorena Andrade Rubio ${ }^{3}$
}

\begin{abstract}
RESUMEN
La importancia del capital social en la explicación de los procesos migratorios es un elemento en torno al cual existe un amplio consenso por parte de los teóricos de las migraciones; como contraste, el fenómeno contrario: el aislamiento de los migrantes de las redes sociales, ha recibido una menor atención por parte de la teoría migratoria. Mientras el capital social contribuye a limar las situaciones de pobreza, el aislamiento social deja a los individuos sin ninguna protección de los malos tiempos. La teoría del capital social sostiene que a medida que los procesos migratorios maduran, los inmigrantes encuentran una urdimbre social cada vez más espesa. Por el contrario, este artículo, fundamentado en una metodología cualitativa, que incluye entrevistas en profundidad a 60 jornaleros migratorios empleados en la comarca citrícola de Tamaulipas y a 43 jornaleros de esta zona empleados en Estados Unidos, concluye que una mayor concentración de la población migrante en los campos agrícolas, en lugar de acrecentar su capital social, conduce a un aumento de su aislamiento social, ya que el incremento de la competencia por el empleo disuelve los vínculos sociales y erosiona los soportes relacionales.
\end{abstract}

Palabras clave: Aislamiento social, capital social, jornaleros, migración, Tamaulipas.

\begin{abstract}
There is a consensus among social scientist about the importance of social capital in the explanation of migration; on the contrary, migration theory has paid less attention to the opposite phenomenon: the isolation of migrants from social networks. While social capital contributes to poverty alleviation, social isolation leaves the individual without any cushion against hard times. Social capital theory explains that as migratory processes mature immigrants find thicker social ties. By contrast, this article, based on a qualitative methodology that includes in depth interviews with 60 migrant farm workers employed in Tamaulipas's orange sector and 43 farm workers from Tamaulipas employed in U.S. farming, concludes that migrant population growth in agricultural fields instead of increasing immigrants social capital augments their social isolation, because the growing competition for scarce employment opportunities dissolves social and relational bonds.
\end{abstract}

Key words: Social isolation, social capital, farm workers, migration, Tamaulipas.

1 Los autores agradecen a PROMEP por el apoyo recibido para la realización de esta investigación a través del proyecto "El problema de la inmigración permanente en la zona citrícola de Tamaulipas" IDCA 6076 clave UAT-CA-73
Artículo recibido el 28 de junio de 2011, aceptado el 29 de enero de 2012 y corregido el 17 de febrero de 2012

2 Universidad Autónoma de Tamaulipas (México). E-mail: sizcara@uat.edu.mx

3 Universidad Autónoma de Tamaulipas (México). E-mail: Kandrade@uat.edu.mx 
Las áreas rurales de Tamaulipas, un estado situado en el noreste de México que comparte 370 kilómetros de frontera con Texas, han experimentado durante las últimas décadas una acentuación de los procesos de expulsión local y atracción externa de mano de obra. Actividades como la caña de azúcar, en el sur del estado, y los cítricos, en el centro, reciben todos los años miles de inmigrantes que proceden principalmente de los estados limítrofes, para ocupar los empleos que dejan vacantes los trabajadores locales que emigran a Estados Unidos o buscan empleos más atractivos en las ciudades fronterizas.

La comarca citrícola de Tamaulipas, compuesta por los municipios de Güémez, Hidalgo, Llera, Padilla y Victoria, experimentó un fuerte desarrollo del sector de cítricos después de los años ochenta debido a tres factores: i) entra al mercado en fresco después de la temporada de Veracruz y San Luis Potosí, vendiendo a precios más altos; ii) presenta un elevado nivel tecnológico; y iii) la creciente apertura a los mercados internacionales (Andrade Rubio, 2010). Esto condujo a un incremento de las necesidades laborales. Sin embargo, en esta zona los jornaleros locales emigran a Estados Unidos porque en sus comunidades padecen problemas de desempleo y subempleo y los salarios son poco atractivos. Como ellos afirman, los ingresos de un día de trabajo en Estados Unidos equivalen a trabajar una semana en Tamaulipas. Por otra parte, los jornaleros migratorios que llegan a la zona citrícola de Tamaulipas lo hacen porque en sus lugares de origen las oportunidades laborales son escasas y los salarios muy bajos. Ellos afirman que en Tamaulipas reciben salarios dos o tres veces más elevados que en sus localidades y que aquí hay más trabajo que allí.

Tamaulipas presenta una larga tradición de migración de su población rural a los Estados Unidos para trabajar en la agricultura. Los braceros tamaulipecos han emigrado tanto de forma indocumentada como a través de programas de trabajadores huéspedes. Hasta hace una década los jornaleros de la comarca citrícola solían cruzar la frontera de modo subrepticio; sin embargo, en los últimos años son cada vez más los que emigran a través del programa $\mathrm{H}-2 \mathrm{~A}^{4}$ de trabajadores huéspedes. Aquellos que no tienen documentos se desplazan sobre todo al sureste de Estados Unidos (principalmente a Texas, Carolina del Norte y Florida); mientras que los que obtuvieron una visa $\mathrm{H}-2 \mathrm{~A}$ trabajan principalmente en Carolina del Norte, Georgia y Washington.

La comarca citrícola de Tamaulipas recibe todos los años a más de cinco mil jornaleros migratorios, y es cada vez mayor el número de inmigrantes que se asientan aquí y ya no regresan a sus lugares de origen. En la década del setenta y ochenta, "coyotes" ${ }^{5}$ o "enganchadores" tamaulipecos comenzaron a trasladarse hacia zonas citrícolas de Veracruz (principalmente a Álamo Temapache, Gutiérrez Zamora y Martínez de la Torre) en busca de mano de obra experimentada en la pizca ${ }^{6}$ de la naranja; a medida que las necesidades laborales se incrementaron, como consecuencia de la expansión de los cítricos y la reticencia de la mano de obra local a aceptar los bajos salarios, los "coyotes" se desplazaron también a San Luis Potosí, y en la última década llegaron hasta Chiapas. Sin embargo, no todos los migrantes vienen con enganchadores. Aquellos que llegan desde estados aledaños pronto descubrieron que venir por libre era más rentable que llegar contratados ${ }^{7}$. Cuando les recluta un "coyote", trabajan todos los días, pero sus salarios son muy bajos; como contraste, cuando vienen por libre se enfrentan a una mayor inseguridad laboral, pero pueden acceder a salarios el doble de altos.

La llegada de jornaleros migratorios a Tamaulipas abarata los salarios y merma las oportunidades laborales de los trabajadores locales. Los empleadores muestran una preferencia por los inmigrantes porque no se quejan, trabajan más aprisa, aguantan más horas trabajando, soportan mejor el calor y se conforman con salarios más bajos. Esto conduce a una exclusión de los locales del

\footnotetext{
4 Visas de trabajo temporal en la agricultura de Estados Unidos.

5 Intermediarios entre los empleadores y los jornaleros, que se encargan de reclutar la mano de obra y de realizar el pago de salarios.

6 Recogida de la naranja.

7 Aunque se trata de contratos verbales que no incluyen prestaciones derivadas de una relación de trabajo formal.
} 
mercado laboral, que optan por emigrar a Estados Unidos, lo cual abre nuevos nichos de empleo e incrementa la demanda de trabajadores migratorios. Por lo tanto, la llegada de jornaleros migratorios a Tamaulipas es efecto y causa de la emigración de los tamaulipecos al país vecino.

El objetivo de este artículo es analizar de modo comparado los procesos de erosión del capital social y ensanchamiento del aislamiento social que sufren tanto los jornaleros de la comarca citrícola de Tamaulipas que emigran a Estados Unidos como los jornaleros migratorios que llegan a esta zona para trabajar en la pizca de la naranja. En primer lugar se describe la metodología utilizada; después se revisan los antecedentes teóricos y empíricos de los conceptos de capital social y aislamiento social; más adelante se analiza la situación de aislamiento social de los jornaleros tamaulipecos empleados en Estados
Unidos, y finalmente se examina el problema de la pérdida de capital social y creciente aislamiento social de los jornaleros migratorios empleados en los cítricos en Tamaulipas.

\section{Metodología}

Esta investigación está fundamentada en un enfoque metodológico cualitativo que permite un adentramiento en aquellos procesos y aspectos que no pueden ser abordados a través de la aplicación de encuestas y cuestionarios, porque no son susceptibles de ser medidos en términos de frecuencia. La técnica utilizada para realizar el acopio de información fue la entrevista en profundidad y el procedimiento para seleccionar a los entrevistados fue el muestreo estratificado intencional. La muestra fue segmentada en dos estratos: i) jornaleros que emigraron a la comarca citrícola de Tamaulipas para trabajar

\section{Cuadro $\mathrm{N}^{\circ} 1$}

Jornaleros que emigraron a la comarca citrícola de Tamaulipas para trabajar en la pizca de la naranja.

\begin{tabular}{|c|c|c|c|c|c|}
\hline \multicolumn{3}{|c|}{ Lugar de procedencia del entrevistado } & \multicolumn{3}{|c|}{ Lugar donde se realizó la entrevista } \\
\hline Municipio & Estado & $\begin{array}{l}\text { Número de } \\
\text { entrevistas }\end{array}$ & Localidad & Municipio & $\begin{array}{l}\text { Número de } \\
\text { entrevistas }\end{array}$ \\
\hline Acayucán & Veracruz & 1 & El Carmen & Guémez & 11 \\
\hline Álamo Temapache & Veracruz & 29 & Guadalupe Victoria & Guémez & 2 \\
\hline Cerro Azul & Veracruz & 2 & Martínez & Guémez & 1 \\
\hline Gutiérrez Zamora & Veracruz & 8 & Santa Rosa & Guémez & 1 \\
\hline Martínez de la Torre & Veracruz & 6 & Subida Alta & Guémez & 6 \\
\hline Naranjos Amatlán & Veracruz & 3 & Francisco I. Madero & Hidalgo & 1 \\
\hline Poza Rica & Veracruz & 1 & Santa Engracia & Hidalgo & 3 \\
\hline Tampico Alto & Veracruz & 1 & El Barretal & Padilla & 34 \\
\hline Tecolutla & Veracruz & 1 & Guadalupe López & Padilla & 1 \\
\hline Tlapacoyan & Veracruz & 2 & & & \\
\hline Tuxpan & Veracruz & 1 & & & \\
\hline Axtla de Terrazas & San Luis Potosí & 1 & & & \\
\hline Cerritos & San Luis Potosí & 1 & & & \\
\hline Ciudad del Maíz & San Luis Potosí & 1 & & & \\
\hline El Naranjo & San Luis Potosí & 1 & & & \\
\hline Tamuín & San Luis Potosí & 1 & & & \\
\hline
\end{tabular}

Fuente: Elaboración propia. 
en la pizca de la naranja, y ii) jornaleros de la citada comarca que emigraron a Estados Unidos en busca de empleos agrarios.

Por una parte, entre los meses de marzo de 2007 y enero de 2010 fueron entrevistados en Padilla, Güémez e Hidalgo sesenta jornaleros migratorios procedentes de Veracruz y San Luis Potosí. Este estrato fue dividido en cuatro subestratos: i) jornaleros migratorios asentados en Tamaulipas; ii) jornaleros que Ilegaron por libre; iii) jornaleros que Ilegaron contratados; y iv) mujeres jornaleras. Dentro de cada subestrato se realizaron 15 entrevistas. Por otra parte, entre los meses de marzo de 2007 y octubre de 2008 fueron entrevistados en Güémez, Hidalgo, Llera, Padilla, y Victoria 43 jornaleros tamaulipecos que emigraron a Estados Unidos: 35 lo hicieron con visas $\mathrm{H}-2 \mathrm{~A}$ y 8 emigraron de modo subrepticio.

En el Cuadro $\mathrm{N}^{\circ} 1$ aparecen los municipios de procedencia de los jornaleros entrevistados que emigraron a Tamaulipas para trabajar en la pizca de la naranja, así como las localidades donde fueron realizadas las entrevistas. Por otra parte, en el Cuadro $\mathrm{N}^{\circ} 2$ aparecen los estados de la Unión Americana donde trabajaron los jornaleros de la comarca citrícola de Tamaulipas entrevistados, así como las localidades donde fueron realizadas las entrevistas (Figura $\mathrm{N}^{\circ} 1$ ).

Cada entrevista fue conducida en dos ocasiones, y todas las conversaciones fueron

\section{Cuadro $\mathrm{N}^{\circ} 2$}

Jornaleros de la comarca citrícola de Tamaulipas que emigraron a Estados Unidos en busca de empleos agrarios

\begin{tabular}{|c|c|c|c|c|}
\hline \multicolumn{2}{|c|}{$\begin{array}{l}\text { Estado de la Unión Americana donde tra- } \\
\text { bajaron }\end{array}$} & \multicolumn{3}{|c|}{ Lugar donde se realizó la entrevista } \\
\hline Estado & Número de entrevistas & Localidad & Municipio & $\begin{array}{l}\text { Número de } \\
\text { entrevistas }\end{array}$ \\
\hline Arkansas & 2 & Güémez & Guémez & 2 \\
\hline Carolina del Norte & 12 & Miraflores & Guémez & 1 \\
\hline Florida & 5 & Servando Canales & Guémez & 3 \\
\hline Georgia & 3 & Guadalupe Victoria & Guémez & 2 \\
\hline Illinois & 1 & Emiliano Zapata & Hidalgo & 2 \\
\hline lowa & 2 & La Crucita & Hidalgo & 1 \\
\hline Minnesota & 1 & Guillermo Zúñiga & Hidalgo & 4 \\
\hline Missouri & 2 & Santa Engracia & Hidalgo & 6 \\
\hline Ohio & 1 & Las Compuertas & Llera & 2 \\
\hline Tennessee & 2 & La Soledad & Padilla & 2 \\
\hline Texas & 5 & Caballeros & Victoria & 2 \\
\hline Virginia & 2 & El Olivo & Victoria & 3 \\
\hline Washington & 5 & La Presa & Victoria & 1 \\
\hline & & Otilio Montaño & Victoria & 2 \\
\hline & & Rancho Nuevo & Victoria & 3 \\
\hline & & Santa Ana & Victoria & 2 \\
\hline & & Vicente Guerrero & Victoria & 4 \\
\hline & & Ciudad Victoria & Victoria & 1 \\
\hline
\end{tabular}

Fuente: Elaboración propia. 
grabadas y transcritas. La primera entrevista tuvo una duración superior a una hora, y la segunda visita tuvo como objeto desarrollar aspectos insuficientemente tratados o abordar temas no tocados en un primer encuentro. Las entrevistas fueron conducidas con un guión abierto acomodado a la experiencia de cada entrevistado; aunque en todas las conversaciones se abordaron unos tópicos comunes relacionados con la decisión de emigrar, la situación sociolaboral, la interacción social y relaciones interpersonales en el lugar de destino.

El proceso de acopio de información estuvo informado por la riqueza heurística de la producción discursiva recabada. Cuando el número de discursos obtenidos permitió interpretar, explicar y describir de forma satisfactoria las diferentes dimensiones del fenómeno social estudiado, se concluyó el trabajo de campo.
Finalmente, en el análisis de los datos se siguió un proceso que incluye tres etapas: i) simplificación de la información y selección de los datos discursivos más relevantes; ii) categorización de la información; y iii) ordenación final de los datos discursivos (Izcara Palacios, 2009: 76).

\section{Capital social versus aislamiento social}

El capital social es la totalidad de los recursos actuales o potenciales asociados a la posesión de una red duradera de relaciones, o el conjunto de recursos basados en la pertenencia a un grupo (Bourdieu, 2001a: 83; 2001b: 148). El capital social tiene un carácter básicamente potencial y designa la posibilidad que tienen los individuos de acceder a recursos por el hecho de pertenecer a redes sociales o estructuras sociales más amplias

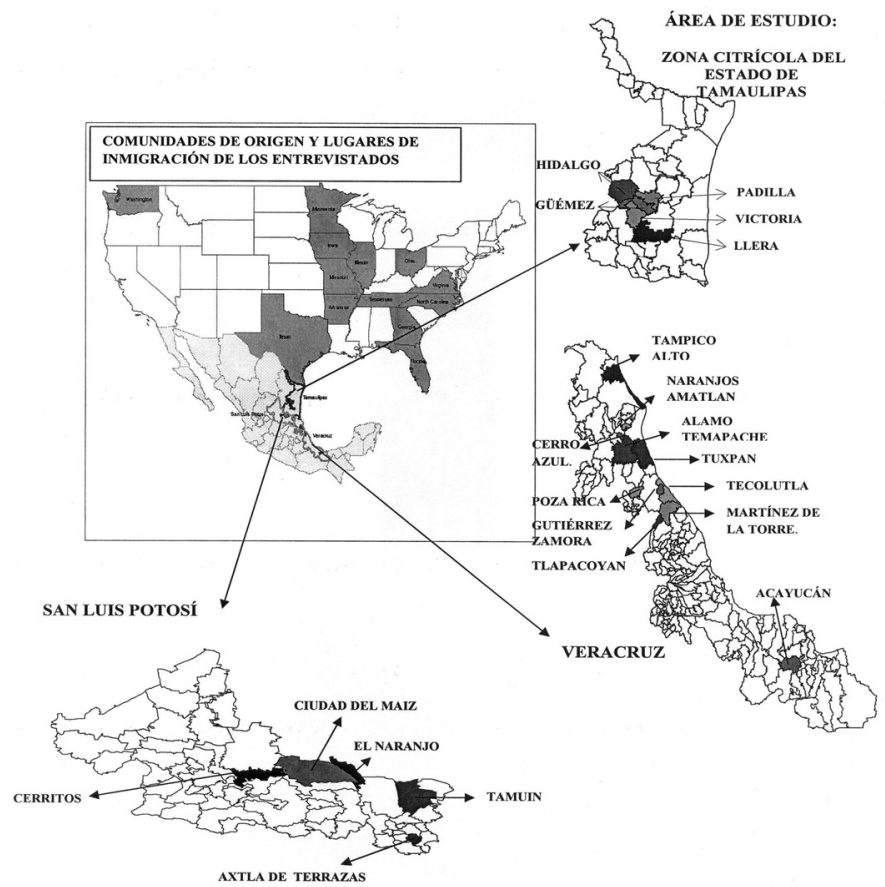

Fuente: Elaboración propia. 
(Portes, 1995: 12; 2010: 681). El aislamiento social es la falta de capital social, e implica un despojamiento de las redes de relaciones sociales, y una privación de aquellos bienes derivados de la pertenencia a dichas redes. El capital social conduce a un arropamiento del individuo; como contraste, el aislamiento social lleva a la soledad, que se deriva de una pérdida de vínculos sociales.

El capital social o conexiones entre individuos, basadas en el parentesco, el paisanaje o la amistad, constituye uno de los factores explicativos de los procesos migratorios que goza de mayor aceptación (Izcara Palacios, 2010b: 57). Una forma de capital social son las redes migratorias (Arango, 2000: 291) o vínculos sociales que ligan los lugares de origen con puntos de destino en la sociedad de acogida y unen a migrantes y no migrantes dentro de una red compleja de roles sociales complementarios y relaciones interpersonales que son mantenidas por expectativas mutuas (Massey et al., 1987: 139). El brote de relaciones interpersonales que ligan al emigrante con personas residentes en las comunidades locales eleva los resultados netos esperados de la emigración (Deléchat, 2001: 476; De Jong et al., 2002: 844), porque favorece el acceso a bienes económicos y empleo, y conduce a una disminución de los costos y los riesgos de la migración (Izcara Palacios, 2011: 42).

Massey et al. (1987: 150) señalan que las redes se fortalecen a medida que maduran y se expanden las conexiones; a diferencia de los pioneros, que carecieron de lazos sociales, quienes emigran después tienen más parientes, amigos y paisanos a quienes recurrir en busca de información y asistencia en el país de inmigración. Es decir, los nuevos migrantes encuentran a su disposición un capital social que alienta nuevos procesos migratorios e incrementa su intensidad. Esto hace que la emigración, lejos de presentar una racionalidad económica y dirigirse hacia espacios caracterizados por salarios más elevados, se desplace hacia aquellas localidades poseedoras de un mayor capital social; de este modo, los espacios de inmigración previa reproducen los procesos migratorios futuros (Gozdziak \& Bump, 2004: 151). Massey et al. (2006: 118) afirman que este capital social es especialmente determinante del primer desplazamiento realizado por el migrante; aunque en viajes posteriores es más importante el capital humano: sus propios conocimientos y experiencias para cruzar la frontera y encontrar trabajo.

La teoría del capital social explica que a medida que las redes se fortalecen y expanden, se convierten en una fuente alentadora de la migración (Massey, 1999: 306), hasta el punto de que los procesos migratorios dejan de depender significativamente de la disponibilidad de empleos o del diferencial salarial entre las sociedades de origen y destino (González González, 2009: 50). De esta forma, el capital social torna los movimientos migratorios en procesos sociales autosostenidos (Castles, 2000: 272), que se autoperpetúan a través de las redes sociales (Massey, 2004: 208). Como contraste, un nivel bajo de capital social genera desconexión social y desincentiva la migración (Chávez et al., 2006: 1026). Como consecuencia, los lugares de destino se caracterizan por un enredamiento de sólidos lazos sociales a los que puede asirse el inmigrante para acceder a recursos como trabajo, vivienda, alimentos, transporte y vida social.

El aislamiento social implica una erosión de las esferas y soportes relacionales del individuo (Raya Díez, 2005: 256), un aislamiento del entorno social, una sociabilidad débil (Suárez, 2004: 34), una degradación progresiva de la participación social (García Martínez y Sánchez Lázaro, 2001), una ausencia de interacción recreacional (García, 2007: 64), una falta del soporte de amigos y familiares (Chávez et al., 2006: 1017); una dificultad para expresar sentimientos personales a otras personas (Hiott et al., 2008: 36), y un aislamiento geográfico (Kim-Godwin et al., 2004: 275; Magaña \& Hovey, 2003: 82).

En el ámbito latinoamericano hasta la década de los ochenta los escenarios de aislamiento social parecían constituir la excepción (Rivera González, 2006: 110). Las redes sociales de apoyo, los sistemas de intercambio recíproco y los vínculos de solidaridad, que se refuerzan ante las adversidades, constituían un alivio ante las situaciones de pobreza y marginación (Suárez, 2004: 4). Lomnitz (1975) señaló cómo las redes de intercambio, el compadrazgo, el cuatismo, 
la reciprocidad y la confianza constituían los mecanismos que posibilitaban la supervivencia de los marginados. El concepto de la erosión de la urdimbre social debido al deterioro de las relaciones sociales de apoyo, resultaba incómodo y producía cierta incredulidad (González de la Rocha y Villagómez Ornelas, 2006: 139). Sin embargo, durante las dos últimas décadas la falta de empleos estables e ingresos regulares dificultaron el intercambio recíproco y condujeron a un deterioro del tejido social, de los lazos y vínculos sociales (Suárez, 2004; Rivera González, 2006: 111). Kaztman (2001: 174) señaló cómo transformaciones recientes en la estructura social de los países latinoamericanos condujeron a un progresivo aislamiento social de los pobres urbanos, porque redujeron las oportunidades para que estos pudiesen acumular capital social individual y colectivo y capital cívico. Por otra parte, McPherson et al. (2006: 369) documentaron un incremento del aislamiento social en la sociedad estadounidense a partir de 1985, que afectó más a la población con menor educación.

El concepto de aislamiento social resulta relevante en el análisis de los procesos migratorios. Estudios recientes sobre los trabajadores migratorios empleados en la agricultura han subrayado cómo el aislamiento social, la soledad y la debilidad de los soportes relaciones y redes de apoyo conduce a los jornaleros a una pérdida de autoestima y ansiedad, y genera sentimientos de tristeza y depresión (Kim-Godwin et al., 2004: 275; García, 2007: 64; Parra-Cardona et al., 2006: 363; Hiott et al., 2008: 36).

Hill (2008: 315) y Holley (2001: 592) han destacado que los trabajadores huéspedes empleados en el sector agrario estadounidense viven en una situación de aislamiento: residen en comunidades remotas donde son ignorados, desconocen qué servicios sociales pueden atender sus necesidades y carecen de las habilidades linguísticas necesarias para solicitar asistencia. Igualmente, Verduzco Igartúa (2007: 29), en un estudio sobre los trabajadores huéspedes mexicanos que trabajan en el sector agrario canadiense, ha subrayado que estos no están integrados en las comunidades canadienses, y padecen condiciones de aislamiento en las granjas. El problema del aislamiento social es más agudo en aquellos trabajadores mexicanos que cruzaron la frontera sin documentos, porque su estancia en los Estados Unidos es más prolongada. García (2008: 20), en una investigación sobre los trabajadores mexicanos empleados en el sector del champiñón en Pensilvania, encontró que los migrantes tenían familiares o conocidos en la región pero nunca los visitaban, y la amistad con algunos compañeros de trabajo no era suficiente para construir un soporte social que les permitiese lidiar con el problema del aislamiento social.

En el caso de los jornaleros migratorios mexicanos empleados en el interior del país, Sánchez y Saldaña (2011: 181), en un reciente estudio sobre el mercado de trabajo de la okra $^{8}$ en Morelos, subrayaron cómo las formas de gestión y los mecanismos de suministro de mano de obra fomentaban la competencia, inhibían la solidaridad entre los trabajadores y generaban tensiones interétnicas. Saldaña Ramírez (2008: 80), en una investigación sobre las prácticas laborales de una agroempresa estadounidense que controla la mayor parte de la producción de angú ${ }^{9}$ en Morelos, señalaba que para disminuir sus costes salariales esta agroindustria trataba de romper los lazos de interdependencia con los trabajadores migrantes y había incitado la competencia entre los jornaleros migratorios y entre estos y los locales. Canabal Cristiani (2005: 93), en un estudio sobre la población migrante de la Montaña de Guerrero empleada en la agricultura de Sinaloa, habla de un aislamiento en campos alejados de la ciudad, un debilitamiento de la presencia de sindicatos y una ausencia de interacción con la población local que los culpa de los males que padecen sus campos y ciudades. Sánchez Muñohierro (2004: 261), en una investigación sobre los indígenas del centro y sur de México que se trasladan a los campos agrícolas del noroeste, ha llamado la atención sobre la necesidad de estos de ocultar su lengua para no ser objeto de abuso, siendo la lengua materna la que permite reproducir los lazos de identificación y apoyo, y generar relaciones de solidaridad.

Por otra parte, Thomas y Znaniecki (2004: 267-286) ya destacaron cómo en ocasiones

\footnotetext{
8 Hortaliza de origen africano.

9 Planta herbácea de origen africano.
} 
la emigración conducía a una pérdida de capital social de los no migrantes (las esposas que quedaban en Polonia), que veían mermar su posición social (sus parientes dejaban de ayudarlas y tener relaciones sociales con ellas) cuando los maridos ya no se solidarizaban con ellas y el lazo conyugal se diluía. Igualmente, investigaciones recientes desarrolladas en el ámbito latinoamericano han subrayado una situación de erosión del capital social e incremento del aislamiento social en los no migrantes, que sufren trastornos relacionados con problemas emocionales por la emigración de esposos e hijos que rompieron la relación de solidaridad con ellos (Álvarez Aragón et al., 2009: 248). Orozco (2009: 184) señala cómo las mujeres abandonadas por sus maridos, que emigraron al norte, enfrentan estigmas sociales y prejuicios que se sobreponen a la solidaridad. Egüez y Acosta (2009: 62) también han destacado la ausencia de capital social, estigmatización y victimización de los hijos e hijas de migrantes.

\section{El aislamiento social de los jornaleros tamaulipecos empleados en Estados Unidos}

Los jornaleros que emigran desde la zona citrícola de Tamaulipas hasta los Estados Unidos para trabajar en la agricultura sufren una grave situación de aislamiento social que se manifiesta en un encerramiento y una pérdida de vínculos con el entorno social, una carencia de interacción recreacional, una sociabilidad débil, y un resquebrajamiento de la urdimbre social debido a la competencia por el empleo (Izcara Palacios, 2010a: 464).

Los trabajadores migratorios tamaulipecos permanecen casi todo el tiempo recluidos en los ranchos. Los campos de labor se encuentran lejos de las poblaciones y no existe ningún sistema de transporte que conecte estos con los centros urbanos; como consecuencia, los trabajadores dependen de sus empleadores para transportarse. Sin embargo, estos son reacios a que sus empleados salgan de los ranchos, porque el ocio y el esparcimiento son actividades que interfieren con la productividad laboral. Expresiones como: "nomás te quedas encerrado como los animales" (David) o "había mucha tensión del encierro" (Donato) hacen referencia a una dolorosa pérdida de libertad de los inmigrantes tamaulipecos empleados en la agricultura estadounidense ${ }^{10}$.

La carencia de soportes relacionales, el sentimiento de soledad generado por la separación de los amigos y familiares y la falta de tiempo de esparcimiento, son factores que generan estrés y hacen que en ocasiones los jornaleros tamaulipecos se planteen regresar a sus hogares y abandonar los ranchos donde trabajan. Como decía Claudio: "nos daba por querernos venir para acá, y pues ese no era el caso, uno se tenía que sacrificar por los que quiere".

La soledad conduce a un ensimismamiento del jornalero y favorece la afloración de situaciones conflictivas en los lugares de trabajo:

"A uno le pega la soledad y es ahí cuando uno se toma unos tragos y pues ya luego uno siente que todo el mundo le ve feo" (Eduardo).

"Ahora me doy cuenta de por qué discutíamos, por todo ese estrés que uno tiene por estar tanto tiempo fuera de casa y el querer ver a tu familia" (Enrique).

El resultado del agrietamiento de los soportes relacionales es un predominio del conflicto en los lugares de trabajo. La urdimbre social está tan quebrada que cualquier factor conduce a enfrentamientos entre la población jornalera. Cuando un nuevo jornalero Ilega a un rancho, frecuentemente sufre el rechazo de aquellos que trabajan allí, porque estos ven amenazadas sus oportunidades económicas. Si un jornalero trabaja más aprisa que otros, no tardan en surgir las envidias y las rivalidades, porque trabajar más significa obtener mayores ingresos que aquellos cuyo rendimiento laboral es menor. En este sentido, Claudio decía: "A los más flojos les daba envidia porque a la hora de la paga, (...) como a ellos les pagaban menos pues se enojaban". Enviar más remesas que otros compañeros de trabajo en ocasiones también genera envidias.

\footnotetext{
10 Todos los nombres de los jornaleros que aparecen en este artículo son seudónimos.
} 
La relación entre los indocumentados y aquellos que tienen papeles casi siempre resulta conflictiva. Los primeros reciben salarios más bajos y su situación laboral es más inestable, esto hace que vean con malos ojos cómo a aquellos que tienen documentos les pagan más sin que se esfuercen tanto como ellos. Aquellos que Ilegan a Estados Unidos de modo temporal mediante el Programa de trabajadores huéspedes, envidian a los indocumentados porque estos son libres de abandonar un empleo si las condiciones sociolaborales son demasiado onerosas; por el contrario, los primeros firmaron contratos que les atan a su empleador y cuando su situación laboral no es satisfactoria, únicamente pueden optar entre regresar a su lugar de origen o tolerar un entorno desventajoso. Los trabajadores autóctonos ven con preocupación cómo los jornaleros migratorios (tanto los indocumentados como aquellos que llegan con visas $\mathrm{H}-2 \mathrm{~A}$ ) merman sus oportunidades económicas ya que los empleadores prefieren a estos últimos porque son más vulnerables y se esfuerzan más en el trabajo. Las siguientes expresiones reflejan el clima tenso que existe entre los trabajadores del campo:

"Nosotros también les teníamos envidia a ellos, los mojaditos ${ }^{11}$, porque ellos se podían ir cuando querían y más si encontraban otro patrón que les pagaba mejor" (Felipe).

"Los escuchábamos decir: ahí vienen los

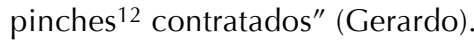

"Nos decían: pinches mojados" (Benjamín).

\section{El aislamiento social de los jornaleros migratorios empleados en Tamaulipas}

Los jornaleros migratorios que llegan a la comarca citrícola de Tamaulipas, desde Veracruz, San Luis Potosí y Chiapas, padecen un problema de aislamiento social, que se

11 Inmigrantes indocumentados, que emigraron de modo subrepticio a los Estados Unidos atravesando el río Bravo.

12 Término despectivo utilizado para calificar a una persona. refleja en un apartamiento del entorno social, una ausencia de interacción con la población local y una ruptura de las redes de relaciones sociales.

La vida de los jornaleros migratorios empleados en la pizca de cítricos en Tamaulipas se desarrolla al margen del entramado social. La sociedad local les rechaza porque viven hacinados en infraviviendas o a la intemperie, carecen de las mínimas condiciones de higiene, siempre están sucios y visten con harapos; de modo que su sola presencia parece atentar contra las normas mínimas de convivencia social. Son invisibles para las instituciones porque no se encuentran residiendo en un lugar específico (emigran a lo largo de la geografía del país siguiendo la diferente estacionalidad de la pizca de la naranja), muchos carecen de la credencial de elector u otra documentación que acredite su identidad y el trabajo que realizan siempre es irregular.

La situación de aislamiento social de los jornaleros migratorios se ha deteriorado en los últimos años. En los años setenta y ochenta llegaron los primeros jornaleros veracruzanos a trabajar en las huertas de naranja tamaulipecas. Tres décadas atrás eran pocos los inmigrantes que llegaban y el grado de aceptación era elevado. Estos se hospedaban en las casas de los jornaleros locales y existía una relación de amistad. Sin embargo, el fuerte crecimiento de la superficie de naranja en Tamaulipas, que pasa de 13 a 38 mil hectáreas entre 1980 y 2000, genera un incremento de la demanda de mano de obra y un crecimiento de los flujos migratorios (Andrade Rubio, 2010: 127). Con el cambio de siglo el número de trabajadores migratorios se elevó por encima de la mano de obra local empleada, y en la actualidad la avalancha de inmigrantes ha mermado las oportunidades económicas de los locales. Esto ha resquebrajado las antiguas redes de solidaridad fraguadas entre la población local y los jornaleros migratorios. Gregorio, un jornalero que emigró por primera vez a Tamaulipas en la segunda mitad de los años ochenta, relataba cómo se había deteriorado la relación con la población local a lo largo del último cuarto de siglo: "Hace mucho nos dejaban quedar en un pasillo de la casa de un señor que también cortaba naranja, y pues ahora ni nos 
habla y pues le dijo a mi jefe (padre) lo siento pero no puedo permitirles quedarse aquí".

\section{La situación de encerramiento}

En la zona citrícola de Tamaulipas los trabajadores migratorios padecen una situación de encerramiento; su vida transcurre entre el trabajo en las huertas de naranja y la reclusión en los pequeños cuartos insalubres donde se alojan. Durante el periodo que permanecen en Tamaulipas no pueden disfrutar de ningún momento de ocio ya que los locales no se lo permiten. La situación de reclusión que padecen los jornaleros migratorios aparece reflejada en el testimonio de Gustavo, quien fue objeto de una paliza, que le impidió trabajar durante varios días, porque invadió el espacio de los locales:

"La vez pasada me agarraron a golpes entre varios, y pues yo fui a un baile porque estuvieron los tigrillos de Nuevo León y pues fui. Ese día ni trabajé y me pusieron una que duré como dos días tirado en el suelo, sin ganas de poder levantarme, y pues aquí la raza del cuarto me traía comida o me dada de lo que ellos comían y pues sí es como decirle, como racismo, nos Ilaman indios cochinos; $y$, pues, ese día de lo que me acuerdo es que me dijeron: y a ti quién te invitó pinche indio maloliente, este baile es para nosotros, tú vete a cortar las naranjas"

Los jornaleros que sufren un mayor grado de encerramiento son los que llegan contratados. Estos reciben salarios más bajos que los demás pizcadores; por lo tanto, para los coyotes es muy importante que los primeros permanezcan aislados del resto de los jornaleros. Si los contratados no se relacionan con otros jornaleros, ni saben cuánto ganan estos, es menos probable que reclamen mayores salarios; por lo tanto, si uno de estos trabajadores es sorprendido hablando con alguien que no pertenece a su cuadrilla puede ser expulsado del grupo. Estos son alojados en espacios alejados de las poblaciones, generalmente en bodegas que no cuentan con ningún servicio, y frecuentemente los coyotes les proporcionan la comida, que luego descuentan de sus salarios, para evitar que se desplacen. Este régimen de trabajo se asemeja a una situación de esclavitud, donde el jornalero trabaja hasta la extenuación, vive aislado, se le prohíbe comunicarse con otra gente que no pertenezca a su grupo, y apenas recibe alimentación. Como señalaba Ignacio: "A mí ya me ha tocado vivir eso cuando me iba a trabajar a Sonora, nos meten en sitios y nos dicen: no hablen con nadie porque al comprador no le gusta, y si sorprenden a alguien hablando con otra cuadrilla de la región ya no trabajará más en la cuadrilla".

Isidro llevaba ocho años viniendo contratado al Ejido Subida Alta en Güémez. Él y los miembros de su cuadrilla vivían aislados en el campo, en una palapa que les había acondicionado el coyote, trabajaban doce horas al día, y nunca se relacionaban con nadie. El mismo coyote les compraba la comida, y los domingos les llevaba a la cabecera municipal para que pudiesen mandar dinero a su familia.

"Aquí nos tienen aislados de todos y sin ir casi ni a las tiendas porque llega uno bien tarde aquí. Trabajamos todo el día desde bien temprano hasta la noche".

Asimismo, Jaime señalaba que él no hablaba con nadie ni conocía nada de Güémez, el municipio donde trabajaba:

"Yo no hablo con nadie de aquí, solo salimos a cenar y a dormir; pues ni conozco nada de aquí, ni como está el ambiente".

\section{La carencia de interacción con la población local}

En la zona citrícola de Tamaulipas no existen lazos entre los locales y los migrantes. Cuando los últimos se relacionan con los primeros, los contactos interpersonales son de carácter exclusivamente comercial. Jacinto se refería del siguiente modo a su relación con la gente de Tamaulipas:

"Ellos (los tamaulipecos) no tienen amistad conmigo, ni yo con ellos (...), es raro que uno conozca uno de aquí, y los que conozco son porque tienen tiendas de abarrotes, esos son los que nos hablan".

Los inmigrantes llegan con la esperanza de trabajar y ahorrar dinero. Ellos no esperan ser bien recibidos ni aceptados por la po- 
blación local; por lo tanto, la mayoría evita relacionarse con la gente para no tener problemas. Graciano, un jornalero veracruzano entrevistado un domingo por la mañana, relataba lo que hacía durante un día de descanso. El día de la entrevista se fue pronto al centro de El Barretal, almorzó en un puesto de comida, luego dio un paseo y más tarde tenía intención de comprarse unas revistas, que hojearía sentado en un banco. Esto tenía que hacerlo antes de que la gente saliese de sus casas, porque en la tarde (cuando los locales salían para caminar, charlar con los amigos o tomar algo en las cantinas) no era aconsejable que él estuviese allí. Únicamente podía caminar libremente o permanecer sentado en un banco del centro urbano si no había nadie allí:

"Ahora estoy aquí solo, y luego me compro unas revistas, hago tiempo y luego ya cuando empieza a salir la gente, ya por la tarde, mejor me voy, para evitar problemas, o algún disgusto con gente ebria o de aquí, que ellos se quieran sentar en la banca y me vean como que quítate, esta banca es mía, mejor me voy y así llevo la fiesta en paz".

La población de la zona citrícola tamaulipeca no acepta que los migrantes se muevan libremente por sus comunidades. Estos son vistos como gente sin valores, que representan una mala influencia para la localidad; por lo tanto, no permiten que invadan los espacios públicos y se entremezclen con los lugareños. Aspectos tan cotidianos como pasear por las calles, sentarse en una banca u observar a la gente puede ser visto como una provocación y detonar un altercado. La frase que más se repite en las entrevistas es que ellos no se relacionan con la población local para evitar problemas. Los jornaleros migratorios se definen como personas que se desplazaron empujados por la necesidad, para poder trabajar y enviar dinero a sus familias; por lo tanto, no desean incomodar a los locales. Los contratados viven apartados; la mayor parte viven y trabajan en las huertas, y los que se hospedan en los núcleos poblacionales también permanecen lejos de la vista de los lugareños porque trabajan todos los días de sol a sol. Casi no se produce ningún encuentro entre los contratados y la población local; aunque los primeros siempre evitan relacionarse con los últimos para no tener problemas. Como decía Lorenzo:

"Nosotros no; nunca les decimos nada, para no tener problemas. No le hablamos a nadie. Nosotros, con decirle que ni conocemos al rentero. El contratista es el que renta la casa, y nosotros venimos a trabajar. Llegamos bien tarde todos los días, y el tiempo que tenemos es para comer".

Como contraste, los jornaleros que Ilegan por libre se alojan en los núcleos urbanos, cerca de las básculas, porque todas las mañanas tienen que desplazarse hasta allí en busca de empleo. Ellos no trabajan todos los días, y muchas veces solo se emplean durante unas pocas horas; de modo que se encuentran inactivos durante una parte importante de su estancia en Tamaulipas. Por lo tanto, aunque buscan estar apartados de la gente, encuentran muchas dificultades para pasar desapercibidos:

"Yo no me mezclo con ellos para no tener problemas, yo soy pues muy apartado de la gente, yo vengo aquí a trabajar a mandar dinero a mi familia" (Javier).

"Nosotros tratamos de no relacionarnos porque nosotros venimos a trabajar por necesidad, no a hacer el mal aquí" (Gregorio).

Tanto los pizcadores migratorios que llegan por libre como los asentados pasan los días recluidos en sus cuartos para evitar tener contacto con la población local y así exponerse a sufrir algún altercado. Lucio decía:

"mire cómo estamos ahora todos metidos en el cuarto; así evitamos los problemas con la gente de aquí, y si nos dicen algo lo mejor es no contestarles. Sí, lo mejor es no hacerles caso de lo que digan para evitar problemas".

Los jornaleros potosinos que Ilegan por libre son quienes sufren una situación de mayor soledad. Aquellos que Ilegan contratados se encuentran arropados por sus compañeros de cuadrilla, y entre los jornaleros veracruzanos, un grupo muy numeroso, existen lazos de amistad. Los potosinos que no vienen con- 
tratados mantienen una relación conflictiva tanto con la población local como con los otros migrantes con quienes trabajan: los veracruzanos. Manuel, un jornalero de Ciudad del Maíz (San Luis Potosí) que llevaba más de un año viviendo en El Barretal (Tamaulipas), decía que cuando no tenía trabajo se pasaba casi todo el día acostado en un costal, porque no tenía amigos ni conocía a nadie con quien conversar:

"Aquí, ni amigos tengo (...) así solo ni la paso bien, mejor me tiendo en un costal y me duermo, últimamente me da mucho por dormirme cuando no tengo trabajo".

\section{La competencia por el empleo y ruptura} de las redes de relaciones sociales

Entre los jornaleros empleados en el sector citrícola de Tamaulipas predomina un clima de tensión ocasionada por unas condiciones de vida precarias, la dureza del trabajo y la competencia por el empleo. Graciano explicaba del siguiente modo la situación de crispación que afectaba a los pizcadores de naranja:

"Es trabajo rudo de hombres, y yo creo que es el cansancio que nos vuelve locos, cualquier mosca nos pica".

La situación más tensa se produce entre los jornaleros locales y los migratorios. Los primeros muestran un profundo resentimiento hacia los últimos, debido a que perciben la llegada de los migrantes como una situación que merma sus oportunidades económicas. Ignacio expresaba del siguiente modo el rencor que guardan los pizcadores locales a los inmigrantes:

"La vez que me hicieron llorar y me desesperé mucho fue un día que un trabajador me pidió dinero, yo no le di porque acabada de pagar la renta y me sobraron 50 pesos, que le di a mi esposa y yo no traía ya nada, y le dije: 'no traigo nada'. Ese día yo había trabajado mucho y me fue bien, pero debía la renta de la casa, y él pensó que yo no le quería dar, y me dijo bueno dame por lo menos 20 pesos, y le dije: 'no traigo nada', y él, muy enojado, me dijo: 'son unos pinches perros, que vienen aquí a quitarnos el trabajo. Tú eres de Veracruz, hoy trabajaste y yo no, desgraciado, y no eres capaz de prestarme nada; perros muertos de hambre que vienen a quitarnos nuestro trabajo'.

Los coyotes, que son quienes contratan a las cuadrillas de pizcadores, trabajan con jornaleros locales y migrantes, pero prefieren a los últimos porque son más conformistas, están más curtidos, trabajan más rápido y aceptan salarios más bajos. Los jornaleros locales raramente pizcan más de una tonelada de naranja al día; como contraste, los inmigrantes pueden pizcar hasta tres toneladas diarias. Por lo tanto, cuando el trabajo escasea son los locales quienes primero quedan desocupados. Es por ello que Marcelino decía:

"Los de aquí nos prefieren a nosotros porque saben cómo cortamos la naranja y pues somos rápidos, y pues ese es el problema de que la gente de aquí no nos quiere, y pues nosotros crecimos en este trabajo, venimos de padres pizcadores, y pues ya estamos curtidos con esto, y pues verá usted, una cuadrilla de Veracruz pues corta bien, y pues solo se necesitan 14 a 16 gentes y una cuadrilla de aquí necesitan más porque son más lentos, no son tan rápidos en este jale".

El presidente municipal de Padilla explicaba el clima de rechazo de los pizcadores locales hacia los jornaleros migratorios como una reacción lógica de los primeros ante una pérdida de sus medios de subsistencia, derivada de la llegada de trabajadores más necesitados, que debido a que aceptan salarios más bajos, dejan a los locales sin empleo, y les obligan a emigrar al país vecino para poder sacar a sus familias adelante,

"Aquí lo que sucede es que los mismos coyotes, que son los que contratan al final al pizcador de naranja, crean un rechazo con la población de aquí, al grado que no los quieren; porque el jornalero local se ve forzado a emigrar a Estados Unidos porque aquí no es contratado por el coyote. Aquí viene mucha gente con un sinfín de quejas de esta gente, pues humilde, que tiene también mucha necesidad de trabajar, como la tienen los pizcadores de aquí. Pero como los de aquí se quedan sin trabajo, pues los pizcadores de aquí los 
rechazan y eso es una reacción hasta de cierto grado pues lógica".

El resentimiento de los jornaleros locales hacia los migrantes y la frustración provocada por los problemas de subempleo y desempleo que padecen los primeros se traduce frecuentemente en agresiones verbales. Como decía Lorenzo:

"Los fines de semana cuando los ve uno, nos dicen cosas. Pero es mejor no contestarles nada, e irse para que no pase nada".

No resulta extraño que en la pizca de la naranja se produzca una separación física entre los jornaleros migratorios y los locales, quienes trabajan en cuadrillas diferentes. Cuando una cuadrilla compuesta por trabajadores tamaulipecos carece de brazos suficientes para completar una tarea, estos suelen invitar a trabajar a alguno de los pizcadores migratorios que esperan cerca de las básculas. Estas circunstancias son aprovechadas por los últimos para intentar hacer amistad con los primeros; pero aun en este escenario el clima sigue siendo tenso y raramente se producen intercambios verbales. Como explicaba Marcos:

"Solamente cuando nos invitan, que les falta alguno, es cuando uno trata de hacer amistad con ellos, pero normalmente ellos casi no hablan con uno".

La competencia por el empleo también resquebraja los soportes relacionales entre los jornaleros migratorios. Aquellos que se asentaron en Tamaulipas no ven con buenos ojos la llegada de sus paisanos, porque esto reduce sus oportunidades de ser empleados. También emergen recelos entre aquellos que vienen contratados y los que llegaron por libre, porque los primeros trabajan todos los días, y los últimos, que cobran salarios algo más elevados, padecen el problema del subempleo. Además, existe una fractura entre los jornaleros veracruzanos, los potosinos y los chiapanecos. Estos últimos, que desconocen el idioma y reciben salarios muy inferiores a los demás, son despreciados por los otros migrantes que les describen como agresivos, vengativos y problemáticos. Asimismo, la relación entre los potosinos y los veracruzanos es problemática ${ }^{13}$. Mariano expresaba de este modo la profunda escisión existente entre los pizcadores de naranja.

"Aquí la gente no nos habla (...) Si usted va a la báscula va a ver un montón de gente que son pizcadores de aquí, todos esperando chamba y luego un poquito más allá todos los de Veracruz, y luego todos los de San Luis Potosí, y así. Pero, aunque estemos puros de Veracruz no nos hablamos; estamos ahí, se acerca un coyote y dice quiero tantos a este precio y los que nos parece nos apuntamos".

Son las mujeres migrantes quienes enfrentan una mayor competencia por el empleo. En las huertas de naranja hay poco empleo para ellas ${ }^{14}$; pero cada vez llegan más mujeres a Tamaulipas. Como decía Natalia: "Cada vez que vengo veo más mujeres aquí". Como consecuencia muchas deben soportar calladas los abusos cometidos por los líderes de las cuadrillas, para obtener empleo. A finales de mayo, cuando disminuye el empleo en la pizca de la naranja, las jornaleras migrantes buscan empleo en las jugueras. Los empleadores dan prioridad a las mujeres inmigrantes sobre las tamaulipecas, porque las primeras hablan menos, no se distraen tanto en el trabajo, son más eficientes y no tienen inconveniente en trabajar en el turno de noche (de 11 de la noche a 7 de la mañana). Esto genera una relación tensa entre ambas. Como señalaba Mayra: "Cuando consigo trabajo en la juguera, pues sí hay envidias con la gente de aquí". Asimismo, Rafaela decía: "Aquí hay mucha gente que quiere esa chamba ${ }^{15}$ (el trabajo en la juguera) y pues nosotras ya estamos yo creo que de más, entonces la gente de ahí (Güémez) pues como que no nos quiere, yo he trabajado y pues ahí pues

13 Algunos veracruzanos se han asentado en las márgenes del río Corona, donde han construido viviendas con materiales de desecho, pero no permiten que los de San Luis construyan aquí sitios donde alojarse. Asimismo, cuando los jornaleros de San Luis Potosí trabajan en las cuadrillas de los veracruzanos, los primeros siempre son discriminados.

${ }^{14}$ Las mujeres son empleadas como contadoras (es decir, cuentan cuantos colotes pizca cada jornalero) y únicamente de modo excepcional pizcan la naranja.

15 Trabajo. 
me echan polilla16". Como ellas repiten en las entrevistas, las mujeres locales les "echan polilla", intentan distraerlas en el trabajo e interrumpirlas, para que los empleadores las despidan. Para las mujeres migrantes es muy duro trabajar en un ambiente tan tenso. Frecuentemente son importunadas por las mujeres tamaulipecas, que las provocan para hacerlas perder los nervios; pero ellas tienen que hacer oídos sordos y aguantar, porque saben que si protagonizan alguna disputa serán despedidas. Como señalaba Paulina, que Ilevaba cinco años viniendo a Tamaulipas para trabajar durante la primavera como contadora y en el verano en la juguera: "Hay mujeres que me quieren provocar, pero yo no dejo lugar para que eso suceda, yo pienso en mis hijos". Asimismo, Patricia señalaba que durante las ocho horas que duraba la jornada laboral ni siquiera iba al baño para no tener problemas con el supervisor, porque las mujeres locales le tendían trampas para que le saliera mal el trabajo.

\section{Conclusión}

La importancia del capital social en la explicación de los procesos migratorios es un elemento en torno al cual existe un amplio consenso por parte de los teóricos de las migraciones. Los modelos teóricos más influyentes señalan que los migrantes utilizan la densa red de relaciones fraguada dentro de su grupo de pertenencia para acceder a recursos como empleo, vivienda, otros bienes económicos e información, de modo que estos se dirigen hacia zonas donde pueden acceder a un capital social que atempera los riesgos de emigrar. Como contraste, el fenómeno contrario: el aislamiento social o deterioro de los vínculos sociales, ha recibido una menor atención por parte de la teoría migratoria.

La teoría del capital social sostiene que a medida que los procesos migratorios maduran, los inmigrantes encuentran una urdimbre social cada vez más espesa; a diferencia de los pioneros, que caminaron a ciegas, las nuevas generaciones hallan el camino trazado. Sin embargo, los ejemplos aquí abordados contradicen este esquema. La emigración

\footnotetext{
16 Hablan mal de uno.
}

de trabajadores rurales tamaulipecos a Estados Unidos en busca de empleos agrarios puede remontarse más de un siglo, y la inmigración de jornaleros que Ilegan a Tamaulipas en busca de oportunidades económicas en la pizca de la naranja puede retrotraerse cuatro décadas; pero, los inmigrantes en lugar de encontrarse cada vez más arropados por soportes relacionales, enfrentan un problema creciente de aislamiento social.

La búsqueda por reducir los costes laborales en la agricultura, tanto en México como en los Estados Unidos, ha conducido a la contratación de fuerza de trabajo asalariada de bajo costo. La ocupación de trabajadores migratorios abarata los salarios y reduce los costes de producción; pero provoca una huida de la mano de obra local, que debe ser reemplazada con la llegada de nuevos migrantes. El resultado de este proceso de expulsión local y atracción externa de mano de obra es una concentración progresiva de la población migrante en los campos agrícolas, que se traduce en un incremento de la competencia por el empleo que disuelve los vínculos sociales y debilita las redes de relaciones sociales. Los migrantes rurales tamaulipecos que Ilegan a los campos agrícolas estadounidenses en busca de empleo sufren el rechazo de aquellos jornaleros que trabajan allí, porque ven en ellos una amenaza a sus oportunidades económicas. En la zona citrícola de Tamaulipas la espesa urdimbre social que había sido tejida décadas atrás entre los jornaleros migratorios y las familias tamaulipecas, ha quedado resquebrajada debido a que la llegada de los primeros ha tornado menos atractivos los empleos locales.

Durante las dos últimas décadas el énfasis de la teoría migratoria en el capital social, y en los beneficios emanados de una red de vínculos que el migrante puede movilizar para acceder a bienes económicos y empleo, ha generado un grado de ocultamiento del drama de la emigración, que es descrita como un proceso guiado por riesgos calculados y mitigados por aquellos recursos materiales e información que son accesibles a través del capital social. Como contraste, los ejemplos estudiados indican que la maduración de los procesos migratorios, lejos de expandir el capital social de los inmigrantes, lo contraen. La estrategia de reducción de los 
costes de operación a través de una elevación continua de los umbrales de productividad por medio de la contratación de mano de obra migrante temporal y precaria hace emerger estrategias individuales de acceso a las escasas oportunidades económicas; esto erosiona las redes sociales de apoyo y los vínculos de solidaridad entre los inmigrantes.

Los ejemplos analizados indican que la expansión de los movimientos migratorios incrementa el aislamiento social de los migrantes. Contrario a lo que plantea la teoría del capital social, los pioneros encuentran soportes relacionales en las comunidades que les acogen; pero cuando los procesos migratorios maduran las redes sociales de apoyo se quiebran porque la llegada de nuevos migrantes, que aceptan condiciones sociolaborales más desfavorables, desplaza a los locales del mercado laboral; esto inhibe la solidaridad entre los trabajadores, forja procesos de segmentación y genera tensiones. Por otra parte, la pérdida de capital social en lugar de desincentivar los flujos migratorios, como predice el citado modelo, alienta la migración. Los procesos migratorios, lejos de autosostenerse independientemente de la disponibilidad de empleos, dependen de la demanda laboral; es decir, son guiados por el reclutamiento de trabajadores menos reivindicativos y más baratos que los locales porque disponen de menos capital social. En el sector citrícola tamaulipeco, los empleadores fomentaron la competencia, favorecieron la ruptura de los lazos sociales y segmentaron a los jornaleros contratando primero trabajadores veracruzanos, reclutando después jornaleros de San Luis Potosí, y dando empleo más tarde a pizcadores chiapanecos y a mujeres migrantes con muy poco capital social. Asimismo, en el sector agrario estadounidense el predominio de inmigrantes aparece relacionado con una preferencia de los empleadores por mano de obra aislada y carente de lazos sociales.

Estos resultados permiten identificar nuevas preguntas de investigación:

¿Los procesos de expulsión local y atracción externa de mano de obra erosionan los lazos y vínculos sociales?

¿Los movimientos migratorios aparecen alentados por el reclutamiento de trabajadores carentes de redes sociales de apoyo?
¿La competencia laboral inhibe la solidaridad y genera aislamiento social?

¿La falta de capital social favorece la migración?

\section{Referencias bibliográficas}

ANDRADE RUBIO, K.L. Exclusión social e inmigración: Los pizcadores de naranja en Tamaulipas. Puebla: Tesis doctoral presentada en la Benemérita Universidad Autónoma de Puebla, 2010.

ÁlVAREZ ARAGÓN, V.; GONZALES DERAS, J. y CASTILLO, C.M. Remesas y mercado de servicios: Estudio de caso Salcajá, Quetzaltenenco. En: GARCÍA ZAMORA, R. y OROZCO, M. Migración internacional, remesas y desarrollo local en América Latina y el Caribe. México: Miguel Ángel Porrúa, 2009, p. 193-260.

ARANGO, J. Explaining Migration: a critical view. International Social Science Journal, 2000, Vol. 52, № 165, p. 283-296.

BOURDIEU, P. El capital social. Apuntes provisionales. Zona Abierta, 2001a, $N^{\circ}$ 94/95, p. 83-87.

BOURDIEU, P. Poder, derecho y clases sociales. Bilbao: Desclée de Brouwer, $2^{a}$ edición, 2001b.

CANABAL CRISTIANI, B. La población migrante de La Montaña de Guerrero y sus ámbitos de reproducción social. En: LEÓN LÓPEZ, A.; CANABAL CRISTIANI, B. y PIMIENTA LASTRA, R. Migración, poder y procesos rurales. México: Plaza y Valdés, 2005, p. 79-107.

CASTLES, S. International migration at the beginning of the twenty-first century: global trends and issues. International Social Science Journal, 2000, Vol. 52, № 165, p. 269-281.

CHÁVEZ, M.L.; WAMPLER, B. \& BURKHART, R.E. Left Out: Trust and Social Capital Among Migrant Seasonal Farmworkers. Social Science Quarterly, 2006, Vol. 87, N 5, p. 1012-1029.

DE JONG, G. F.; CHAMRATRITHIRONG, A. \& TRAN, Q.G. For Better, For Worse: Life 
Satisfaction Consequences of Migration. International Migration Review, 2002, Vol. $36, \mathrm{~N}^{\circ} 3$, p. 838-863.

DELÉCHAT, C. International Migration Dynamics: The Role of Experience and Social Networks. Labour, 2001, Vol. 15, N³, p. 457-486

EGÜEZ, P. y ACOSTA, A. Economía local y remesas en América Latina. El caso de Catamayo. En: GARCÍA ZAMORA, R. y OROZ$\mathrm{CO}, \mathrm{M}$. Migración internacional, remesas y desarrollo local en América Latina y el Caribe. México: Miguel Ángel Porrúa, 2009, p. 5-78.

GARCÍA, V. Meeting a Binational Research Challenge: Substance Abuse Among Transnational Mexican Farmworkers in the United States. The Journal of Rural Health, 2007, N²3, p. 61-67.

GARCíA, V. Problem Drinking among transnacional mexican migrants: Exploring migrant Status and Situational Factors. Human Organization, 2008, Vol. 67, № 1, p. $12-24$.

GARCÍA MARTÍNEZ, J. A. y SÁNCHEZ LÁZARO, A. M. Para profundizar en la temática de la exclusión. Revista Anales de Pedagogía, 2001, No 19, p. 171-184.

GOZDZIAK, E. M. \& BUMP, M.N. Poultry, Apples, and New Immigrants in the Rural Communities of the Shenandoah Valley: An Ethnographic Case Study. International Migration, 2004, Vol. 42, № 1, p. 149-164.

GONZÁLEZ DE LA ROCHA, M. y VILLAGÓMEZ ORNELAS P. Espirales de desventajas: Pobreza, ciclo vital y aislamiento social. En: SARAVÍ GONZALO A. De la pobreza a la exclusión, continuidades y rupturas de la cuestión social en América Latina. México: CIESAS, 2006, p. 137-165

GONZÁLEZ GONZÁLEZ, E. Características e implicaciones de la migración mexicana a Estados Unidos. En: HERRERA-LASSO, L. México, país de migración. México: Siglo XXI, 2009, p. 19-72.

HILL, J. Binational Guestworker Unions: Moving Guestworkers into the House of
Labor. Fordham Urban Law Journal, 2008, № 35, p. 307-338.

HIOTT, A.E.; GRZYWACZ, J.G.; DAVIS, S.W.; QUANDT, S.A. \& ARCURY, T.A. Migrant Farmworkers Stress: Mental Health Implications. The Journal of Rural Health, 2008, Vol. 24, No 1, p. 32-39.

HOLLEY, M. Disadvantaged by Design: How the Law Inhibits Agricultural Guest Workers from Enforcing their Rights. Hofstra Labor \& Employment Law Journal, 2001, N ${ }^{\circ}$ 18 , p. 573-621.

IZCARA PALACIOS, S.P. La praxis de la investigación cualitativa. México: Plaza y Valdés, 2009.

IZCARA PALACIOS, S.P. Migración irregular y aislamiento social. Los jornaleros tamaulipecos indocumentados en los Estados Unidos. Revista Internacional de Sociología, 2010a, Vol. 68, N², p. 453-472.

IZCARA PALACIOS, S.P. La adicción a la mano de obra ilegal. Jornaleros tamaulipecos en Estados Unidos. Latin American Research Review, 2010b, Vol. 45, № 1, p. 55-75

IZCARA PALACIOS, S.P. Redes migratorias versus demanda laboral: Los elementos que moldean los procesos migratorios. Convergencia. Revista de Ciencias Sociales, 2011, No 57, p. 39-59.

KAZTMAN, R. Seducidos y abandonados: el aislamiento social de los pobres urbanos. Revista de la CEPAL, 2001, № 75, p. 171189.

KIM-GODWIN, Y.S. \& BECHTEL, G. Stress Among Migrant and Seasonal Farmworkers in Rural Southeast North Carolina. The Journal of Rural Health, 2004, Vol. 20, №3, p. 271-278.

LOMNITZ, L.A. Cómo sobreviven los marginados. México: Siglo XXI, 1975.

MAGAÑA, C.G. \& HOVEY, J.D. Psychosocial Stressors Associated with Mexican Migrant Farm Workers in the Midwest United States. Journal of Immigrant Health, 2003, Vol. 5, № 2, p. 75-86. 
MASSEY, D. International Migration at the Dawn of the Twenty-first Century: The Role of the State, Population and Development Review, Vol. 25, №5, p. 303-322

MASSEY, D. Social and Economic Aspects of Immigration. Annals of the New York Academy of Sciences, 2004, N 1038, p. 206-212.

MASSEY, D.; ALARCÓN, R.; DURAND, J. \& GONZÁlEZ, H. Return to Aztlan. The Social Process of Internacional Migration from Western Mexico. Los Angeles: University of California Press, 1987.

MASSEY, D.; DURAND, J. y RIOSMENA, F. Capital social, política social y migración desde comunidades tradicionales y nuevas comunidades de origen en México. Revista Española de Investigaciones Sociológicas, 2006, Nº116, p. 97-121.

MCPHERSON, M.; SMITH-LOVIN, L. \& BRASHEARS, M.E. Social Isolation in America: Changes in Core Discussion Networks over Two Decades. American Sociological Review, 2006, $\mathrm{N}^{\circ} 71$, p. 353375.

OROZCO, M. Entre la dificultad y la esperanza. Remesas y economía local en Latinoamérica. En: GARCÍA ZAMORA, R. y OROZCO, M. Migración internacional, remesas y desarrollo local en América Latina y el Caribe. México: Miguel Ángel Porrúa, 2009, p. 153-192.

PARRA-CARDONA, J.R.; BULOCK, L.A.; IMIG, D.R.; VILLARRUEL, F.A. \& GOLD, S.J. Trabajando duro todos los días: Learning from the Life Experiences of Mexican-Origin Migrant Familias. Family Relations, 2006, Vol. 55, № 3, p. 361-375.

PORTES, A. Economic Sociology and the Sociology of Immigration: A Conceptual Overview. En: PORTES, A. The Economic Sociology on Immigration. Nueva York: Russell Sage Foundation, 1995, p. 1-14.

PORTES, A. Un diálogo Norte-Sur: El progreso de la teoría en el estudio de la migración internacional y sus implicaciones. En: ARIZA, M. y PORTES, A. El país transnacional. Migración mexicana y cambio social a través de la frontera. México: Miguel Ángel Porrúa, 2010, p. 651-702.

RAYA DÍEZ, E. Categorías sociales y personas en situación de exclusión. Una aproximación desde el País Vasco. Revista Cuadernos de Relaciones Laborales, 2005, Vol. 23, $N^{\circ} 2$, p. 247- 267.

RIVERA GONZÁLEZ, J.G. Crisis y refuncionalización de las redes de reciprocidad familiares: el caso de sectores medios en la Ciudad de México. Economía, Sociedad y Territorio, 2006, Vol. VI, N²1, p. 87-118.

SALDAÑA RAMÍREZ, A. La experiencia de una agroempresa estadounidense en la producción de hortalizas de exportación en Morelos. En: CASTRO DOMINGO, P. Dilemas de la migración en la sociedad posindustrial. México: Miguel Ángel Porrúa, 2008, p. 65-81.

SÁNCHEZ, K. y SALDAÑA, A. Configuración de corrientes migratorias alrededor del mercado de trabajo de la okra en Morelos. En: LARA FLORES, S.M. Los "encadenamientos migratorios" en espacios de agricultura intensiva. México: Miguel Ángel Porrúa, 2011, p. 151-211.

SÁNCHEZ MUÑOHIERRO, L. Jornaleros indígenas en el noroeste de México. En: ESCÁRCEGA, S y VARESE, S. La ruta mixteca. México: Universidad Nacional Autónoma de México, 2004, p. 229-268.

SUÁREZ, A.L. Erosión de capital social en contextos de aislamiento social. Buenos Aires: Trabajo presentado en el IV Encuentro Anual de Investigación del Área de Sociología del Instituto de Ciencias de la UNGS, 2004.

THOMAS, W.I. y ZNANIECKI, F. El campesino polaco en Europa y en América. Madrid: BOE, 2004.

VERDUZCO IGARTÚA, G. Lecciones del Programa de Trabajadores Temporales Mexicanos en la agricultura de Canadá. Una buena práctica amenazada. En: SANTIBÁÑEZ ROMELLÓN, J. Trabajo temporal y migración internacional a partir de la experiencia México-Canadá. México: Miguel Ángel Porrúa, 2007, p. 11-46. 
